\title{
Instrument self-noise and sensor misalignment
}

\author{
A. Gerner and G. Bokelmann \\ Department of Meteorology and Geophysics, University of Vienna, Austria
}

Correspondence to: A. Gerner (andreas.gerner@univie.ac.at)

Received: 30 June 2013 - Accepted: 28 August 2013 - Published: 17 September 2013

\begin{abstract}
In this study we investigate self-noise of RefTek ${ }^{\mathrm{TM}}$ 151-60A "Observer" broadband seismometers (flat to velocity between $50 \mathrm{~Hz}$ down to $T_{0}=60 \mathrm{~s}, f_{0} \approx 17 \mathrm{mHz}$ ) using the coherency analysis method introduced by Sleeman et al. (2006).

We present a self-noise model for this type of sensor and compare it to the self-noise models of the standard observatory sensor STS-2 (Streckeisen) and RefTek's 151-120 broadband seismometer, which both have natural periods $T_{0}$ of $120 \mathrm{~s}$.

We further report on the sensitivity of this technique to sensor misalignment and our success of eliminating leakage of the omnipresent microseism noise into self-noise estimates by numerically rotating seismic traces in order to find real self-noise.
\end{abstract}

\section{Motivation}

With ever-improving seismic instruments, processing methods and computational capabilities it becomes important to distinguish between the various sources of noise that are recorded in seismic data (Ringler et al., 2011).

One of these sources of noise is the seismograph itself, which is why for an assessment of its suitability for a given purpose and for reasons of quality control it is necessary to have a means of estimating its self-noise.

Sleeman et al. (2006) propose a method of calculating the self-noise of seismographs using coherency analysis. Assuming the seismic background noise simultaneously recorded by three collocated, co-aligned sensors to be identical, they compute auto-power spectra $\left(P_{i i}\right)$ and cross-power spectra $\left(P_{i j}\right)$ of the recorded data in order to eliminate the signal of coherent background noise, and thus isolate and identify the incoherent portion, which can then be attributed to the instrument. If the sensors are well isolated from non-seismic

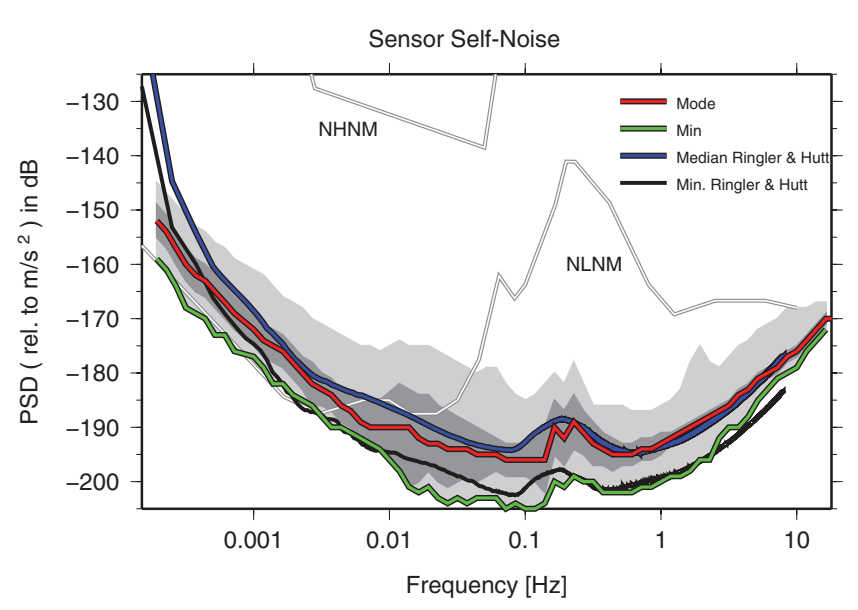

Fig. 1. Self-Noise model of the STS-2 as published by Sleeman and Melichar (2012). In all of the self-noise curves the signature of Earth's microseisms, which are the dominant source of natural seismic background noise in the pictured frequency range (Peterson, 1993), can clearly be recognized (also see: Ringler and Hutt, 2010).

sources, then this procedure can be used to get an estimate of their self-noise.

\section{Sensor alignment and finding true self-noise}

While aforementioned method is intriguingly simple and robust in ideal cases, the computed self-noise estimates strongly depend upon the exact alignment of the collocated instruments.

Non-aligned sensors will record background-noise incoherently, and thus this noise will not cancel out completely for three sensors $i, j, k$. Instead, incoherently recorded 


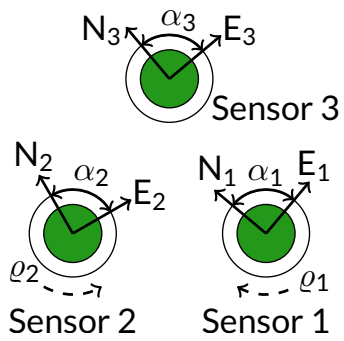

Fig. 2. Schematic view illustrating the misalignment between three sensors' horizontal components and the rotation performed about their $z$ axes in order to align two sensors with the third $\left(\varrho_{i}\right)$.

background-noise will "leak" into self-noise estimates $N$ of each of the sensors:

$N_{i i}=P_{i i}-P_{j i} \cdot \frac{P_{i k}}{P_{j k}}$.

Sleeman and Melichar (2012) show that a misalignment of two sensors on the order of $0.2^{\circ}$ may cause a significant portion $(\approx 10 \mathrm{~dB})$ of the background noise to remain in the selfnoise spectrum.

This value of $0.2^{\circ}$ is in the range of the max. guaranteed error in orthogonality of the STS-2's sensing axes (Sleeman and Melichar, 2012). For the RefTek 151-60A instruments this error in orthogonality is $<0.5^{\circ}$ (personal communication RefTek).

An exact alignment of the components of three collocated sensors is hard to realize by setup alone. Optimal alignment can subsequently be achieved by numerically rotating the recorded traces, which has been described for nonorthogonal, three dimensional rotations for example by Tasič and Runovc (2013). They perform rotations for the STS-2 sensor, which physically has three non-orthogonal sensing axes. In our case, with sensors physically having orthogonal sensing axes, we focus on aligning horizontal traces only, and thus restrict ourselves to orthogonal, two dimensional rotations of the horizontal components about their $z$ axis, searching for the angles of rotation that minimize their self-noise level in the microseismic band.

During fall 2011 we installed 15 151-60A sensors (nominal generator constant $G=2000 \mathrm{Vs} \mathrm{m}^{-1}$, with digitizers RefTek RT130) at the Conrad-Observatory in Austria and selected the quietest period of nine hours of continuous recordings for our self-noise computations.

For the best recordings of 11 sensors we performed a gridsearch for optimal angles of rotation with minimum selfnoise in the approximate frequency range of the microseismic band $(0.02-0.7 \mathrm{~Hz})$ for both horizontal components separately $\left(\varrho_{N} \& \varrho_{E}, \Delta \varrho=0.02^{\circ}\right)$ and all possible permutations of triples of the 11 sensors (Fig. 2 for a schematic view). An example of this grid-search is shown in Figs. 3 and 4, results for all 11 sensors are listed in Table A1.

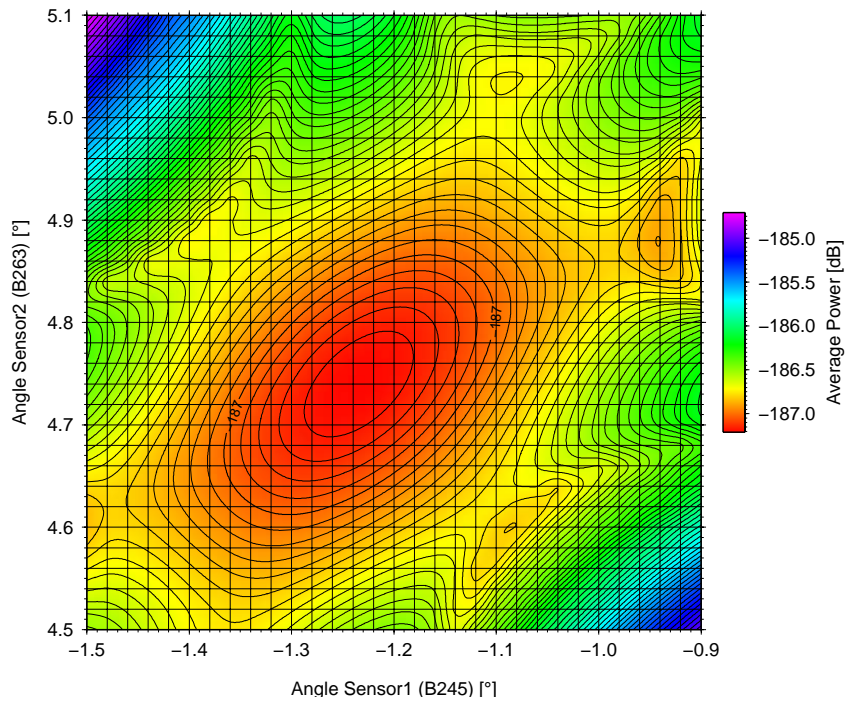

Fig. 3. Mean self-noise in the $0.02-0.7 \mathrm{~Hz}$ frequency range from incrementally rotating the N/S-components of sensors B245 and B263 in order to align them with B267.

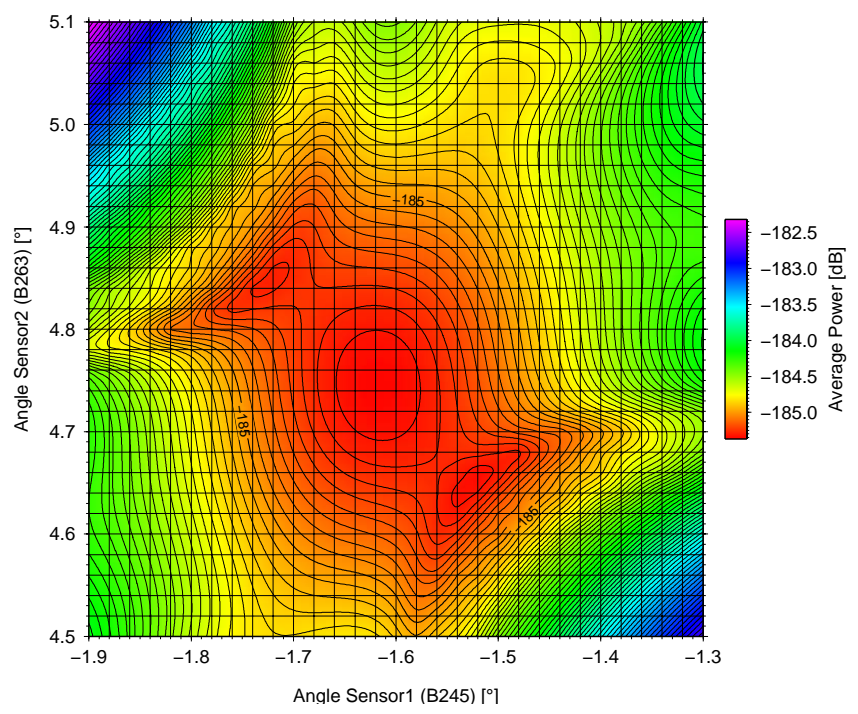

Fig. 4. Results from above experiment for the E/W-component. The increment used during the grid-search to find optimal alignment was $\Delta \varrho=0.02^{\circ}$.

The comparably large number of identical sensors installed enabled us to further compute self-noise curves for the vertical components of 13 out of the 15 sensors and all their possible permutations of triples without prior numerical rotation. From these computations we selected 306 self-noise curves in order to produce a statistically significant self-noise model for the vertical component of the RefTek 151-60A, and compare it to the available self-noise models of the STS2 and the RefTek 151-120. 


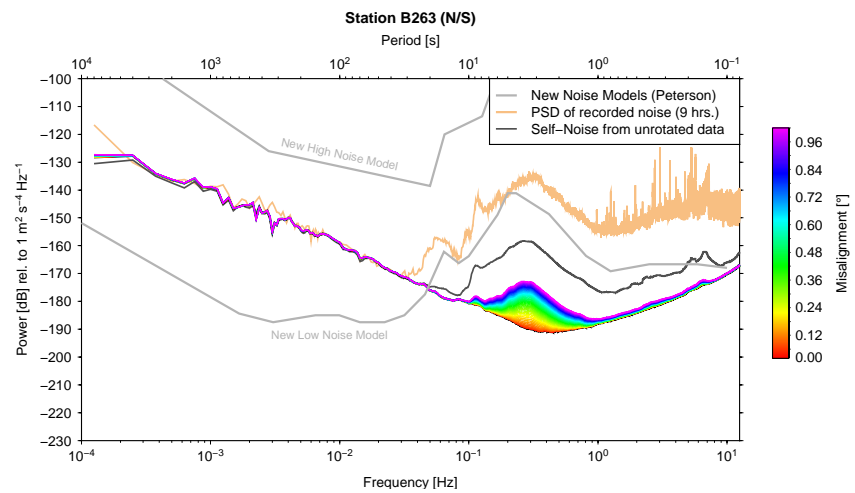

Fig. 5. Sensitivity study as to how much the misalignment of one sensor in a triple of sensors influences self-noise estimates particularly in the microseismic band. As can be seen, the leakage is quite significant, reaching more than $10 \mathrm{~dB}$ at $0.3 \mathrm{~Hz}$ for $0.5^{\circ}$ of misorientation. Self-noise estimates of the other two sensors (not shown here) exhibit only very small variations since they are still well aligned with each other.

\section{Results}

Our experiments showed that, given a good vertical alignment of the sensors, we were able to completely remove the leakage of microseism noise into the self-noise estimates through correct numerical rotation of the horizontal components (Fig. 5) of the RefTek 151-60A. The sensitivity study depicted in Fig. 5 only included misalignment of one of the three sensors and resulted in a leakage of $\approx 10 \mathrm{~dB}$ of microseismic noise into the self-noise estimate at $0.3 \mathrm{~Hz}$ for $0.5^{\circ}$ of misalignment. While the misalignment of one single sensor primarily manifests itself in the self-noise results of that very sensor, a misalignment of all three sensors results in much higher values of leakage, comparable to those found through numerical experiments by Sleeman and Melichar (2012).

With above-mentioned sensitivity to misalignment of the coherency method applied in our study, and taking into account the maximum possible, physical accuracy of the orthogonality of the sensing axes of a sensor constrained by the accuracy during the production process $\left(<0.5^{\circ}\right.$ for the 151-60A), we performed our calculations for both horizontal components separately in order to confirm the manufacturer's specifications.

Assuming that the N/S- and E/W-sensing axes of three sensors were perfectly orthogonal, the best angles of rotation for both horizontal components that minimize leakage of microseism noise into self-noise estimates, can be expected to be equal. From our experiments performed with a comparably large number of identical sensors however, we have found that the maximum difference between optimal angles $\varrho_{\mathrm{N} / \mathrm{S}}$ and $\varrho_{\mathrm{E} / \mathrm{w}}$ was $0.83^{\circ} \pm 0.03^{\circ}$, which corresponds to a best assumable error in orthogonality of $0.42^{\circ} \pm 0.03^{\circ}$ and is in very good agreement with RefTek's specifications mentioned before (see Table A1).

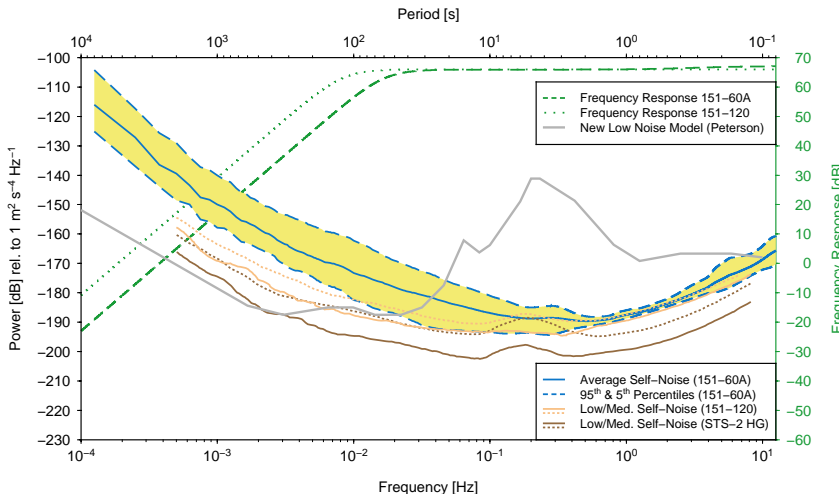

Fig. 6. Self-noise model for the RefTek 151-60A calculated from data $(9 \mathrm{~h})$ recorded at the Conrad Observatory by 15 collocated sensors. Self-noise was computed for all possible permutations of triples of sensors (vertical components only). From the results, 306 self-noise curves of 13 sensors were selected for derivation of this model. To best estimate the instrument's true self-noise, curves of clearly misaligned triples of sensors were excluded.

Further, by means of calculating self-noise estimates for unrotated vertical components of 13 identical sensors in all possible permutations of triples, we were able to establish a self-noise model for the RefTek 151-60A sensor (Fig. 6) and compare it to the published self-noise models of the STS-2 and the RefTek 151-120, which both are sensitive in a wider frequency range and have lower self-noise.

\section{Conclusions}

By means of the experiments performed in this study we have shown that, for the RefTek 151-60A sensor, we were able to remove the omnipresent peak in background noise caused by Earth's microseisms from self-noise estimates through numerically rotating seismic traces of two sensors in order to optimally align them with the third. While remains of this microseisms signal can be found in self-noise models of several sensors (Ringler and Hutt, 2010), but are well below the New Low Noise Model (NLNM, Peterson, 1993), we demonstrate that their complete removal through numerical rotation is possible for the RefTek 151-60A. Additionally, we can conclude that outside the microseisms band, self-noise estimates are not significantly compromised by sensor-misalignment.

Using the coherency technique proposed by Sleeman et al. (2006), which turned out to be intriguingly stable even in the presence of suboptimal background-noise conditions (PSD in Fig. 5), we were able to derive a self-noise model for the vertical component of the RefTek 151-60A broadband sensor from a number of 13 sensors, hence producing a statistically significant result. Moreover, the use of this technique renders our results directly comparable to those published recently by other authors. We are thus able to assess the quality and performance of the RefTek 151-60A in terms of its self-noise 
Table A1. Table listing the optimal angles of rotation $\left(\varrho_{\mathrm{N}} / \varrho_{\mathrm{E}}\right)$ found to best align the horizontal components of 11 RefTek $151-60 \mathrm{~A}$ sensors. Differences of the angles of rotations $\left(\varrho_{\mathrm{E}}-\varrho_{\mathrm{N}}\right)$ are listed boldfaced below them. From these, the best assumable error in orthogonality between N/S- and E/W-components is $\left(\varrho_{\mathrm{E}}-\varrho_{\mathrm{N}}\right) / 2$.

\begin{tabular}{|c|c|c|c|c|c|c|c|c|c|c|c|}
\hline Sensor $3=$ & \multirow[t]{2}{*}{ B209 } & \multirow[t]{2}{*}{ B220 } & \multirow[t]{2}{*}{ B221 } & \multirow[t]{2}{*}{ B224 } & \multirow[t]{2}{*}{ B225 } & \multirow[t]{2}{*}{ B226 } & \multirow[t]{2}{*}{ B234 } & \multirow[t]{2}{*}{ B245 } & \multirow[t]{2}{*}{ B263 } & \multirow[t]{2}{*}{ B267 } & \multirow[t]{2}{*}{ B32C } \\
\hline Sensor $1 / 2$ & & & & & & & & & & & \\
\hline B209 & 0.00 & $\begin{array}{r}0.30 / 0.70 \\
\mathbf{0 . 4 0}\end{array}$ & $\begin{array}{r}-5.31 /-5.46 \\
-\mathbf{0 . 1 5}\end{array}$ & $\begin{array}{r}0.02 / 0.27 \\
\mathbf{0 . 2 5}\end{array}$ & $\begin{array}{r}3.27 / 3.66 \\
\mathbf{0 . 3 9}\end{array}$ & $\begin{array}{r}0.57 / 1.03 \\
\mathbf{0 . 4 6}\end{array}$ & $\begin{array}{r}-0.59 /-0.04 \\
\mathbf{0 . 5 5}\end{array}$ & $\begin{array}{r}2.15 / 2.83 \\
\mathbf{0 . 6 8}\end{array}$ & $\begin{array}{r}-3.82 /-3.55 \\
\mathbf{0 . 2 7}\end{array}$ & $\begin{array}{r}0.90 / 1.23 \\
\mathbf{0 . 3 3}\end{array}$ & $\begin{array}{r}-0.32 /-0.04 \\
\mathbf{0 . 2 8}\end{array}$ \\
\hline B220 & $\begin{array}{r}-0.30 /-0.70 \\
-\mathbf{0 . 4 0}\end{array}$ & 0.00 & $\begin{array}{r}-5.61 /-6.16 \\
-\mathbf{0 . 5 5}\end{array}$ & $\begin{array}{r}-0.28 /-0.43 \\
-\mathbf{0 . 1 5}\end{array}$ & $\begin{array}{r}2.97 / 2.96 \\
-0.01\end{array}$ & $\begin{array}{r}0.27 / 0.33 \\
\mathbf{0 . 0 6}\end{array}$ & $\begin{array}{r}-0.89 /-0.74 \\
\mathbf{0 . 1 5}\end{array}$ & $\begin{array}{r}1.85 / 2.13 \\
\mathbf{0 . 2 8}\end{array}$ & $\begin{array}{r}-4.12 /-4.25 \\
-\mathbf{0 . 1 3}\end{array}$ & $\begin{array}{r}0.60 / 0.53 \\
-0.07\end{array}$ & $\begin{array}{r}-0.62 /-0.74 \\
-\mathbf{0 . 1 2}\end{array}$ \\
\hline B221 & $\begin{array}{r}5.31 / 5.46 \\
\mathbf{0 . 1 5}\end{array}$ & $\begin{array}{r}5.61 / 6.16 \\
\mathbf{0 . 5 5}\end{array}$ & 0.00 & $\begin{array}{r}5.33 / 5.73 \\
\mathbf{0 . 4 0}\end{array}$ & $\begin{array}{r}8.58 / 9.12 \\
\mathbf{0 . 5 4}\end{array}$ & $\begin{array}{r}5.90 / 6.47 \\
\mathbf{0 . 5 7}\end{array}$ & $\begin{array}{r}4.72 / 5.42 \\
\mathbf{0 . 7 0}\end{array}$ & $\begin{array}{r}7.46 / 8.29 \\
\mathbf{0 . 8 3}\end{array}$ & $\begin{array}{r}1.49 / 1.91 \\
\mathbf{0 . 4 2}\end{array}$ & $\begin{array}{r}6.21 / 6.69 \\
\mathbf{0 . 4 8}\end{array}$ & $\begin{array}{r}4.99 / 5.52 \\
\mathbf{0 . 5 3}\end{array}$ \\
\hline B224 & $\begin{array}{r}-0.02 /-0.27 \\
-\mathbf{0 . 2 5}\end{array}$ & $\begin{array}{r}0.28 / 0.43 \\
\mathbf{0 . 1 5}\end{array}$ & $\begin{array}{r}-5.33 /-5.73 \\
-\mathbf{0 . 4 0}\end{array}$ & 0.00 & $\begin{array}{r}3.25 / 3.39 \\
\mathbf{0 . 1 4}\end{array}$ & $\begin{array}{r}0.55 / 0.76 \\
\mathbf{0 . 2 1}\end{array}$ & $\begin{array}{r}-0.63 /-0.28 \\
\mathbf{0 . 3 5}\end{array}$ & $\begin{array}{r}2.13 / 2.56 \\
\mathbf{0 . 4 3}\end{array}$ & $\begin{array}{r}-3.84 /-3.82 \\
\mathbf{0 . 0 2}\end{array}$ & $\begin{array}{r}0.88 / 0.96 \\
\mathbf{0 . 0 8}\end{array}$ & $\begin{array}{r}-0.34 /-0.21 \\
\mathbf{0 . 1 3}\end{array}$ \\
\hline B225 & $\begin{array}{r}-3.27 /-3.66 \\
-\mathbf{0 . 3 9}\end{array}$ & $\begin{array}{r}-2.97 /-2.96 \\
\mathbf{0 . 0 1}\end{array}$ & $\begin{array}{r}-8.58 /-9.12 \\
-\mathbf{0 . 5 4}\end{array}$ & $\begin{array}{r}-3.25 /-3.39 \\
-\mathbf{0 . 1 4}\end{array}$ & 0.00 & $\begin{array}{r}-2.68 /-2.65 \\
\mathbf{0 . 0 3}\end{array}$ & $\begin{array}{r}-3.86 /-3.70 \\
\mathbf{0 . 1 6}\end{array}$ & $\begin{array}{r}-1.12 /-0.83 \\
\mathbf{0 . 2 9}\end{array}$ & $\begin{array}{r}-7.09 /-7.21 \\
-\mathbf{0 . 1 2}\end{array}$ & $\begin{array}{r}-2.37 /-2.43 \\
-\mathbf{0 . 0 6}\end{array}$ & $\begin{array}{r}-3.59 /-3.60 \\
-\mathbf{0 . 0 1}\end{array}$ \\
\hline B226 & $\begin{array}{r}-0.57 /-1.03 \\
-\mathbf{0 . 4 6}\end{array}$ & $\begin{array}{r}-0.27 /-0.33 \\
-0.06\end{array}$ & $\begin{array}{r}-5.90 /-6.47 \\
-\mathbf{0 . 5 7}\end{array}$ & $\begin{array}{r}-0.55 /-0.76 \\
-\mathbf{0 . 2 1}\end{array}$ & $\begin{array}{r}2.68 / 2.65 \\
-0.03\end{array}$ & 0.00 & $\begin{array}{r}-1.18 /-1.04 \\
\mathbf{0 . 1 4}\end{array}$ & $\begin{array}{r}1.57 / 1.82 \\
\mathbf{0 . 2 5}\end{array}$ & $\begin{array}{r}-4.40 /-4.56 \\
-\mathbf{0 . 1 6}\end{array}$ & $\begin{array}{r}0.32 / 0.23 \\
-\mathbf{0 . 0 9}\end{array}$ & $\begin{array}{r}-0.90 /-0.95 \\
-\mathbf{0 . 0 5}\end{array}$ \\
\hline B234 & $\begin{array}{r}0.59 / 0.04 \\
-\mathbf{0 . 5 5}\end{array}$ & $\begin{array}{r}0.89 / 0.74 \\
\mathbf{- 0 . 1 5}\end{array}$ & $\begin{array}{r}-4.72 /-5.42 \\
-\mathbf{0 . 7 0}\end{array}$ & $\begin{array}{r}0.63 / 0.28 \\
-\mathbf{0 . 3 5}\end{array}$ & $\begin{array}{r}3.86 / 3.70 \\
-0.16\end{array}$ & $\begin{array}{r}1.18 / 1.04 \\
-\mathbf{0 . 1 4}\end{array}$ & 0.00 & $\begin{array}{r}2.75 / 2.87 \\
\mathbf{0 . 1 2}\end{array}$ & $\begin{array}{r}-3.23 /-3.51 \\
-\mathbf{0 . 2 8}\end{array}$ & $\begin{array}{r}1.50 / 1.28 \\
-0.22\end{array}$ & $\begin{array}{r}0.28 / 0.10 \\
-\mathbf{0 . 1 8}\end{array}$ \\
\hline B245 & $\begin{array}{r}-2.15 /-2.83 \\
-\mathbf{0 . 6 8}\end{array}$ & $\begin{array}{r}-1.85 /-2.13 \\
-\mathbf{0 . 2 8}\end{array}$ & $\begin{array}{r}-7.46 /-8.29 \\
-\mathbf{0 . 8 3}\end{array}$ & $\begin{array}{r}-2.13 /-2.56 \\
-\mathbf{0 . 4 3}\end{array}$ & $\begin{array}{r}1.12 / 0.83 \\
-\mathbf{0 . 2 9}\end{array}$ & $\begin{array}{r}-1.57 /-1.82 \\
-\mathbf{0 . 2 5}\end{array}$ & $\begin{array}{r}-2.75 /-2.87 \\
-\mathbf{0 . 1 2}\end{array}$ & 0.00 & $\begin{array}{r}-5.97 /-6.37 \\
-\mathbf{0 . 4 0}\end{array}$ & $\begin{array}{r}-1.23 /-1.62 \\
-\mathbf{0 . 3 9}\end{array}$ & $\begin{array}{r}-2.46 /-2.77 \\
-\mathbf{0 . 3 1}\end{array}$ \\
\hline B263 & $\begin{array}{r}3.82 / 3.55 \\
-\mathbf{0 . 2 7}\end{array}$ & $\begin{array}{r}4.12 / 4.25 \\
\mathbf{0 . 1 3}\end{array}$ & $\begin{array}{r}-1.49 / 1.91 \\
-\mathbf{0 . 4 2}\end{array}$ & $\begin{array}{r}3.84 / 3.82 \\
-\mathbf{0 . 0 2}\end{array}$ & $\begin{array}{r}7.09 / 7.21 \\
\mathbf{0 . 1 2}\end{array}$ & $\begin{array}{r}4.40 / 4.56 \\
\mathbf{0 . 1 6}\end{array}$ & $\begin{array}{r}3.23 / 3.51 \\
\mathbf{0 . 2 8}\end{array}$ & $\begin{array}{r}5.97 / 6.37 \\
\mathbf{0 . 4 0}\end{array}$ & 0.00 & $\begin{array}{r}4.74 / 4.75 \\
\mathbf{0 . 0 1}\end{array}$ & $\begin{array}{r}3.50 / 3.51 \\
\mathbf{0 . 0 1}\end{array}$ \\
\hline B267 & $\begin{array}{r}-0.90 /-1.23 \\
-\mathbf{0 . 3 3}\end{array}$ & $\begin{array}{r}-0.60 /-0.53 \\
\mathbf{0 . 0 7}\end{array}$ & $\begin{array}{r}-6.21 /-6.69 \\
-\mathbf{0 . 4 8}\end{array}$ & $\begin{array}{r}-0.88 /-0.96 \\
-\mathbf{0 . 0 8}\end{array}$ & $\begin{array}{r}2.37 / 2.43 \\
\mathbf{0 . 0 6}\end{array}$ & $\begin{array}{r}-0.32 /-0.23 \\
\mathbf{0 . 0 9}\end{array}$ & $\begin{array}{r}-1.50 /-1.28 \\
\mathbf{0 . 2 2}\end{array}$ & $\begin{array}{r}1.23 / 1.62 \\
\mathbf{0 . 3 9}\end{array}$ & $\begin{array}{r}-4.74 /-4.75 \\
-\mathbf{0 . 0 1}\end{array}$ & 0.00 & $\begin{array}{r}-1.23 /-1.25 \\
-\mathbf{0 . 0 2}\end{array}$ \\
\hline B32C & $\begin{array}{r}0.32 / 0.04 \\
-\mathbf{0 . 2 8}\end{array}$ & $\begin{array}{r}0.62 / 0.74 \\
\mathbf{0 . 1 2}\end{array}$ & $\begin{array}{r}-4.99 /-5.52 \\
-\mathbf{0 . 5 3}\end{array}$ & $\begin{array}{r}0.34 / 0.21 \\
-\mathbf{0 . 1 3}\end{array}$ & $\begin{array}{r}3.59 / 3.60 \\
\mathbf{0 . 0 1}\end{array}$ & $\begin{array}{r}0.90 / 0.95 \\
\mathbf{0 . 0 5}\end{array}$ & $\begin{array}{r}-0.28 /-0.10 \\
\mathbf{0 . 1 8}\end{array}$ & $\begin{array}{r}2.46 / 2.77 \\
\mathbf{0 . 3 1}\end{array}$ & $\begin{array}{r}-3.50 /-3.51 \\
-\mathbf{0 . 0 1}\end{array}$ & $\begin{array}{r}1.23 / 1.25 \\
\mathbf{0 . 0 2}\end{array}$ & 0.00 \\
\hline
\end{tabular}

and in relation to other types of broadband sensors. With its self-noise below the NLNM, approx. in the range of frequencies where its response is flat to velocity, we conclude that the RefTek 151-60A would be suitable for sites with noise levels that would prohibit taking advantage of the lower self-noise levels of the STS-2 and the RefTek 151-120 (e.g. islands, shallow vaults).

Further, and maybe more importantly, our results suggest that the coherency technique applied for estimation of instrument self-noise for both horizontal components separately, is sufficiently sensitive to misalignment of the sensors' components that it can be used to test the manufacturer's specifications as to the orthogonality of the sensing axes, given that experiments are conducted for a large number of sensors. For the instruments used in our experiments we found the orthogonality between the two horizontal sensing axes to be in good agreement with the parameters provided by RefTek.

\section{References}

Sleeman, R., van Wettum, A., and Trampert, J.: Three-Channel Correlation Analysis: A New Technique to Measure Instrumental Noise of Digitizers and Seismic Sensors, Bull. Seism. Soc. Am., 96, 258-271, 2006.

Ringler, A. T., Hutt, C. R., Evans, J. R., and Sandoval, L. D.: A Comparison of Seismic Instrument Noise Coherence Analysis Techniques, Bull. Seism. Soc. Am., 101, 558-567, 2011.

Sleeman, R. and Melichar, P.: A PDF Representation of the STS2 Self-Noise Obtained from One Year of Data Recorded in the Conrad Observatory, Austria, Bull. Seism. Soc. Am., 102, 587597, 2012.

Tasič, I. and Runovc, F.: Determination of a seismometer's generator constant, azimuth, and orthogonality in three-dimensional space using a reference seismometer, J. Seismol., 17, 807-817, 2013.

Peterson, J.: Observations and Modelling of Seismic Background Noise, Open File Report, U.S. Geological Survey, Albuquerque, 93-322, 1993.

Ringler, A. T. and Hutt, C. R.: Self-Noise Models of Seismic Instruments, Seism. Res. Let., 81, 972-983, 2010. 